\title{
Iron Powder-CuI Cooperative Catalytic System in Sonogashira Cross-Coupling Reaction
}

\author{
Ngoc Thang Tran, ${ }^{\dagger}$ Chan Sik Cho, ${ }^{\dagger, *}$ Ho-Sang Sohn, and Sang Chul Shim ${ }^{\dagger}$ \\ Department of Materials Science and Metallurgical Engineering, Kyungpook National University, Daegu 702-701, Korea \\ †Department of Applied Chemistry, Kyungpook National University, Daegu 702-701, Korea. ${ }^{*}$-mail: cscho@knu.ac.kr \\ Received December 13, 2010, Accepted January 17, 2011
}

Key Words : Aryl iodides, Terminal alkynes, Iron powder, Carbon-carbon bond formation, Sonogashira coupling

The transition metal-catalyzed sp-carbon-sp ${ }^{2}$-carbon bond forming reaction by the cross-coupling of terminal alkynes with aryl and vinyl halides (or triflates) is well known as Sonogashira cross-coupling reaction. ${ }^{1-4}$ This protocol has been widely used as a powerful synthetic tool for the synthesis of prevalent and valuable intermediates for pharmaceuticals and organic materials. ${ }^{1-4}$ Since the coupling intrinsically catalyzed by $\mathrm{Pd}\left(\mathrm{PPh}_{3}\right)_{4}$ and $\mathrm{CuI}$ was discovered in $1975,{ }^{5}$ many elegant catalytic systems which facilitate such a coupling under the milder and cheaper conditions have been developed by the tuning of a ligand combined with the kind of palladium catalysts. ${ }^{1-4}$ Furthermore, besides such palladium based systems, several catalytic systems which are inexpensive and benign to the environment have been developed for both an academic viewpoint and a large scale industrial application. For example, many copper salts combined with appropriate ligands have been used as an alternative to palladium based systems for Sonogashira cross-coupling reaction. ${ }^{6-15}$ In connection with this report, iron salts have recently had an upsurge as a promising catalyst in carbon-carbon bond forming reactions due to their natural abundance, low cost and environmental friendliness. ${ }^{16-20}$ Thus, a number of iron catalysts have also been applied to Sonogashira coupling. For representative examples, Mao and Vogel groups have reported that terminal alkynes are readily cross-coupled with aryl iodides in the presence of $\mathrm{Fe}(\mathrm{acac})_{3}$ in combination with $\mathrm{CuI}$ without an additional ligand. ${ }^{21-22}$ It was also disclosed by Liu group that $\mathrm{Fe}_{2} \mathrm{O}_{3} / N, N, N^{\prime}, N^{\prime}$-tetramethylethylenediamine catalytic system can be used for such a coupling by the assistance of $\mathrm{Cu}(\mathrm{acac})_{2}$ cocatalyst. ${ }^{23}$ It is also worthy to note that terminal alkynes were found to be cross-coupled with aryl iodides in the presence of $\mathrm{FeCl}_{3}$ combined with $N, N^{\prime}$-dimethylethylenediamine or $\mathrm{PPh}_{3}$ without further addition of a copper ancillary. ${ }^{24,25}$ Under these circumstances, during the course of our ongoing studies on transition metal-catalyzed carboncarbon and carbon-nitrogen bond forming reactions, ${ }^{26-36}$ herein this report describes an efficient iron powder/CuI/ $\mathrm{PPh}_{3}$-catalyzed cross-coupling reaction between terminal alkynes and aryl iodides leading to coupled alkynes.

Phenylacetylene (1a) and iodobenzene (2a) were chosen as the model reactants for optimizing reaction conditions.
Several attempted representative results under various conditions are listed in Table 1. Treatment of 1a with 1.2 equiv of 2a in DMF in the presence of a catalytic amount of iron powder (10 mol \% based on 1a), $\mathrm{PPh}_{3}(10 \mathrm{~mol} \%$ based on 1a) and $\mathrm{CuI}\left(10 \mathrm{~mol} \%\right.$ based on 1a) along with $\mathrm{K}_{2} \mathrm{CO}_{3}$ for $10 \mathrm{~h}$ afforded diphenylacetylene (3a) in $95 \%$ isolated yield with complete conversion of $\mathbf{1 a}$ and concomitant formation of a trace amount of 1,4-diphenylbuta-1,3-diyne by the homo-coupling of 1a on GLC (run 1). Lower reaction rate and yield were observed in the absence of either $\mathrm{PPh}_{3}$, or $\mathrm{Fe}$ powder, or CuI (runs 2-4). Even though the reaction proceeds in the absence of iron powder, the yield of 3a was lower than that of the reaction by the addition of iron powder (run 3). It is known that $\mathrm{CuI} / \mathrm{PPh}_{3}$ catalytic system catalyzes cross-coupling of terminal alkynes and aryl iodides in $\mathrm{H}_{2} \mathrm{O}$ at a higher temperature in a pressure tube..$^{37} \mathrm{It}$ is worthwhile to note that the reaction proceeds even in the absence of $\mathrm{CuI}$ (run 4). These results indicate that the coexistence of Fe powder, $\mathrm{PPh}_{3}$ and $\mathrm{CuI}$ is necessary for the effective

Table 1. Optimization of conditions for the reaction of phenylacetylene (1a) with phenyl iodide (2a) ${ }^{a}$

\begin{tabular}{|c|c|c|c|c|c|}
\hline & $1 a$ & & & $3 a$ & \\
\hline Run & Catalytic systems & Bases & Solvents & $\begin{array}{l}\text { Time } \\
\text { (h) }\end{array}$ & $\begin{array}{c}\text { Yield } \\
(\%)\end{array}$ \\
\hline 1 & $\mathrm{Fe}$ powder/CuI/ $\mathrm{PPh}_{3}$ & $\mathrm{~K}_{2} \mathrm{CO}_{3}$ & DMF & 10 & 95 \\
\hline 2 & Fe powder/CuI & $\mathrm{K}_{2} \mathrm{CO}_{3}$ & DMF & 10 & 82 \\
\hline 3 & $\mathrm{CuI} / \mathrm{PPh}_{3}$ & $\mathrm{~K}_{2} \mathrm{CO}_{3}$ & DMF & 10 & 80 \\
\hline 4 & Fe powder/ $\mathrm{PPh}_{3}$ & $\mathrm{~K}_{2} \mathrm{CO}_{3}$ & DMF & 10 & 76 \\
\hline 5 & $\mathrm{Fe}$ powder/CuI/ $\mathrm{PPh}_{3}$ & - & DMF & 10 & 6 \\
\hline 6 & $\mathrm{Fe}$ powder/CuI/ $\mathrm{PPh}_{3}$ & $\mathrm{~K}_{3} \mathrm{PO}_{4}$ & DMF & 10 & 99 \\
\hline 7 & $\mathrm{Fe}$ powder/CuI/ $\mathrm{PPh}_{3}$ & $\mathrm{Cs}_{2} \mathrm{CO}_{3}$ & Toluene & 1 & 73 \\
\hline 8 & $\mathrm{Fe}$ powder/CuI/ $\mathrm{PPh}_{3}$ & $\mathrm{Cs}_{2} \mathrm{CO}_{3}$ & Dioxane & 1 & 64 \\
\hline 9 & $\mathrm{Fe}$ powder/CuI/ $\mathrm{PPh}_{3}$ & $\mathrm{Cs}_{2} \mathrm{CO}_{3}$ & PEG-400 & 1 & 19 \\
\hline 10 & $\mathrm{Fe}$ powder/CuI/ $\mathrm{PPh}_{3}$ & $\mathrm{Cs}_{2} \mathrm{CO}_{3}$ & DMF & 1 & 99 \\
\hline 11 & $\mathrm{CuI} / \mathrm{PPh}_{3}$ & $\mathrm{Cs}_{2} \mathrm{CO}_{3}$ & DMF & 10 & 77 \\
\hline
\end{tabular}

${ }^{a}$ Reaction conditions: 1a $(1 \mathrm{mmol}), 2 \mathrm{2a}(1.2 \mathrm{mmol})$, Fe powder $(0.1$ $\mathrm{mmol})$, CuI $(0.1 \mathrm{mmol}), \mathrm{PPh}_{3}(0.1 \mathrm{mmol})$, base $(2 \mathrm{mmol})$, solvent $(2$ $\mathrm{mL}$ ), at $110^{\circ} \mathrm{C}$, under $\mathrm{N}_{2}$. 
formation of 3a (runs 1-4). However, when the reaction was carried out in the absence of base under the employed conditions, 3a was produced in only $6 \%$ yield with incomplete conversion of both substrates (run 5). Replacing $\mathrm{K}_{2} \mathrm{CO}_{3}$ by $\mathrm{K}_{3} \mathrm{PO}_{4}$ under the same reaction conditions resulted in quantitative yield of $\mathbf{3 a}$ (run 6). As a result, after further elaborated tuning with base, reaction time and solvent, the best result in terms of both product 3a yield and complete conversion of $\mathbf{1 a}$ is best accomplished by the standard set of reaction conditions shown in run 10 of Table 1 (runs 7-11).

On the other hand, the certificate of analysis of commercial Fe powder $(99.9 \%$, Strem Chemicals, Inc.) shows several elements such as As $(<3 \mathrm{ppm}), \mathrm{Pb}(<4 \mathrm{ppm})$ and

Table 2. Fe powder $/ \mathrm{PPh}_{3} / \mathrm{CuI}$-catalyzed Sonogashira cross-coupling of terminal alkynes $\mathbf{1}$ with aryl iodides $\mathbf{2}^{a}$

$$
\begin{aligned}
& \mathrm{R}=+\mathrm{I}=\mathrm{Ar} \underset{\mathrm{Fe} \mathrm{powder} / \mathrm{Cul} / \mathrm{PPh}_{3}, \mathrm{Cs}_{2} \mathrm{CO}_{3}}{\mathrm{DMF}} \mathrm{R}=\mathrm{Ar} \\
& (\mathrm{R}=\text { aryl, heteroaryl, vinyl, alkyl })
\end{aligned}
$$

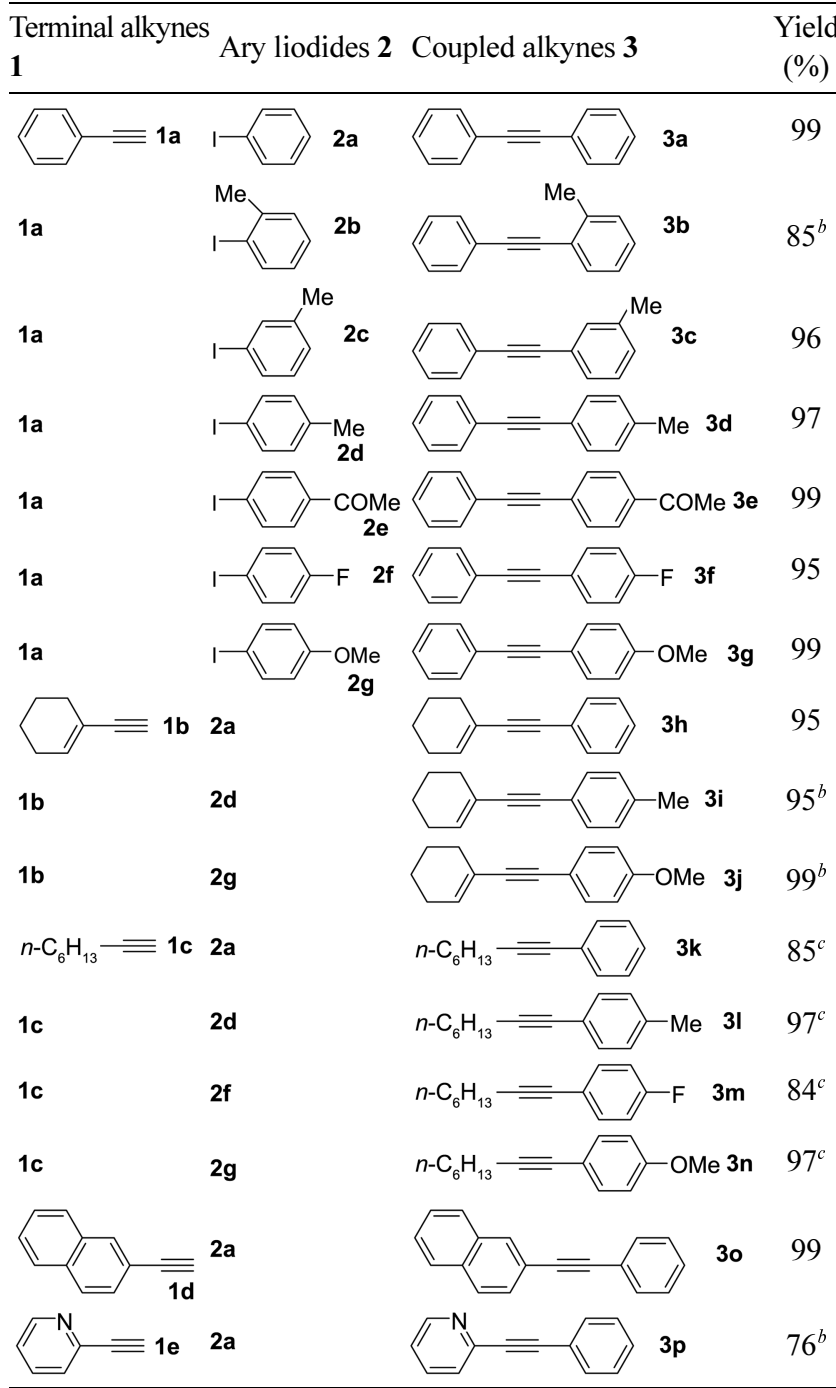

${ }^{a}$ Reaction conditions: $1(1 \mathrm{mmol}), \mathbf{2}(1.2 \mathrm{mmol}), \mathrm{Fe}$ powder $(0.1 \mathrm{mmol})$, $\mathrm{PPh}_{3}(0.1 \mathrm{mmol}), \mathrm{CuI}(0.1 \mathrm{mmol}), \mathrm{Cs}_{2} \mathrm{CO}_{3}(2 \mathrm{mmol}), \mathrm{DMF}(2 \mathrm{~mL})$, at $110{ }^{\circ} \mathrm{C}$, for $1 \mathrm{~h}$, under $\mathrm{N}_{2} .{ }^{b}$ For $10 \mathrm{~h} .{ }^{c}$ For $20 \mathrm{~h}$.
$\mathrm{Hg}(<2 \mathrm{ppm})$ along with insoluble materials in aqueous acid $(0.05 \%)$. We also confirmed that no Pd contaminant in $\mathrm{Fe}$ powder was observed by ICP-AES (inductively coupled plasma-atomic emission spectroscopy). However, even though $\mathrm{Cu}$ was detected in 9 ppm by ICP-AES, similar treatment of 1a with $\mathbf{2 a}$ under the catalytic system of $\mathrm{CuI}$ (1500 ppm based on 1a)/ $\mathrm{PPh}_{3} / \mathrm{Cs}_{2} \mathrm{CO}_{3} / \mathrm{DMF}$ afforded 3a in only $6 \%$ yield.

For investigating the reaction scope, the optimized condition was subjected to the reaction of various terminal alkynes $\mathbf{1}$ with aryl iodides $\mathbf{2}$ and several representative results are summarized in Table 2. Phenylacetylene (1a) reacted with an array of aryl iodides (2a-g) having electrondonating and -withdrawing substituents on the aromatic ring to afford the corresponding coupled alkynes (3a-g) in quantitative isolated yields. The product yield was considerably affected by the position of the substituent on $\mathbf{2}$, whereas the electronic nature of that had no relevance to the product yield. With ortho-substituted aryl iodide $\mathbf{2 b}$, the coupled product yield was lower than that when meta- and para-substituted aryl iodides (2c-g) were used. Thus, a longer reaction time was actually needed for the satisfactory coupling with $\mathbf{2 b}$. In the reaction of vinyl alkyne, 1ethynylcyclohex-1-ene (1b) with several aryl iodides, the corresponding coupled alkynes were also obtained in quantitative yields. Here again, lower reaction rate was observed with $\mathbf{2 d}$ and $\mathbf{2 g}$. Lower reaction rate and yield were observed with alkyl alkyne 1c when compared with those of aryl and vinyl alkynes. The coupling of 1c with several aryl iodides afforded coupled alkynes (3k-n) in the range of $84-97 \%$ yields for a longer reaction time. From the reaction between 2-ethynylnaphthalene (1d) and 2a, the corresponding coupled alkyne 30 was also produced in quantitative yield. Heteroaryl alkyne, 2-ethynylpyridine (1e) was also crosscoupled with $\mathbf{2 a}$ to give 2-(2-phenylethynyl)pyridine (3p) in $76 \%$ yield for $10 \mathrm{~h}$.

In summary, we have demonstrated that the cross-coupling of aryl, vinyl, alkyl substituted terminal alkynes with aryl iodides was catalyzed by Fe powder $/ \mathrm{PPh}_{3} / \mathrm{CuI}$. The present reaction provides a cheaper cooperative catalytic system in Sonogashira cross-coupling reaction and further study for a catalytic role of iron powder is currently under investigation.

\section{Experimental Section}

Melting points were determined on a Standford Research Inc. MPA100 automated melting point apparatus. GLC analyses were carried out with a Shimadzu GC-17A instrument equipped with a CBP10-S25-050 column (Shimadzu, fused silica capillary column, $0.33 \mathrm{~mm} \times 25 \mathrm{~m}, 0.25 \mu \mathrm{m}$ film thickness) using nitrogen as carrier gas. The isolation of pure products was carried out via column (silica gel 60, 70230 mesh, Merck) or thin layer (silica gel $60 \mathrm{GF}_{254}$, Merck) chromatography. Iron powder $(99.9 \%)$ was purchased from Strem Chemicals Inc. Commercially available organic and inorganic compounds were used without further purification except for solvents, which were distilled prior to use. 
General Procedure for Fe Powder/PPh $/$ /CuI-Catalyzed Cross-Coupling Reaction of Terminal Alkynes with Aryl Iodides. A mixture of alkyne (1 mmol), aryl iodide (1.2 $\mathrm{mmol})$, iron powder $(0.0056 \mathrm{~g}, 0.1 \mathrm{mmol}), \mathrm{PPh}_{3}(0.026 \mathrm{~g}$, $0.1 \mathrm{mmol})$, $\mathrm{CuI}(0.019 \mathrm{~g}, 0.1 \mathrm{mmol}), \mathrm{Cs}_{2} \mathrm{CO}_{3}(0.652 \mathrm{~g}, 2$ $\mathrm{mmol})$ and DMF $(2 \mathrm{~mL})$ was placed in a sealable reactor with Teflon cap (Radleys Discovery Technologies). After the system was flushed with $\mathrm{N}_{2}$, the mixture was stirred at $110{ }^{\circ} \mathrm{C}$ for a required time. After the reaction mixture was cooled down to room temperature, it was filtered through a short silica gel column (ethyl acetate as eluent) to eliminate inorganic salts. Removal of the solvent left a crude mixture, which was separated by column or thin layer chromatography (silica gel, ethyl acetate-hexane mixture) to give coupled alkynes 3. All coupled alkynes prepared by the above procedure were characterized by GLC and melting point comparison with authentic samples synthesized by known methods and purchased from chemical companies.

Acknowledgment. This research was supported by Basic Science Research Program through the National Research Foundation of Korea (NRF) funded by the Ministry of Education, Science and Technology (2010-0007563).

\section{References}

1. Sonogashira, K. Metal-catalyzed Cross-coupling Reactions; Diederich, F., de Meijere, A., Eds.; Wiley-VCH: Weinheim, 2004; Vol. 1, pp 319-345.

2. Doucet, H.; Hierso, J. C. Angew. Chem. Int. Ed. 2007, 46, 834.

3. Chinchilla, R.; Nájera, C. Chem. Rev. 2007, 107, 874

4. Plenio, H. Angew. Chem. Int. Ed. 2008, 47, 6954.

5. Sonogashira, K.; Tohda, Y.; Hagihara, N. Tetrahedron Lett. 1975, 4467.

6. Saejueng, P.; Bates, C. G.; Venkataraman, D. Synthesis 2005, 1706.

7. Tang, B. X.; Wang, F.; Li, J. H.; Xie, Y. X.; Zhang, M. B. J. Org. Chem. 2007, 72, 6294.

8. Biffis, A.; Scattolin, E.; Ravasio, N.; Zaccheria, F. Tetrahedron Lett. 2007, 48, 8761.
9. Wang, Z. L.; Wang, L.; Li, P. H. Synthesis 2008, 1367.

10. Mao, J. C.; Guo, J.; Ji, S. J. J. Mol. Cat. A: Chem. 2008, $284,85$.

11. Li, J. H.; Li, J. L.; Wang, D. P.; Pi, S. F.; Xie, Y. X.; Zhang, M. B.; Hu, X. C. J. Org. Chem. 2007, 72, 2053.

12. Deng, C. L.; Xie, Y. X.; Yin, D. L.; Li, J. H. Synthesis 2006, 3370

13. Liu, F.; Ma, D. J. Org. Chem. 2007, 72, 4844.

14. Cacchi, S.; Fabrizi, G.; Parisi, L. M. Org. Lett. 2003, 5, 3843.

15. Monnier, F.; Turtaut, F.; Duroure, L.; Taillefer, M. Org. Lett. 2008 10, 3203.

16. Bolm, C.; Legros, J.; Paith, J. L.; Zani, L. Chem. Rev. 2004, 104, 6217.

17. Taillefer, M.; Xia, N.; Ouali, A. Angew. Chem. Int. Ed. 2007, 46, 934.

18. Correa, A.; Carril, M.; Bolm, C. Angew. Chem. Int. Engl. 2008, 47, 2880.

19. Volla, C. M. R.; Vogel, P. Angew. Chem. Int. Engl. 2008, 47, 1305.

20. Bézier, D.; Darcel, C. Adv. Synth. Catal. 2009, 351, 1732.

21. Mao, J.; Xie, G.; Wu, M.; Guo, J.; Ji, S. Adv. Synth. Catal. 2008, $350,2477$.

22. Volla, C. M. R.; Vogel, P. Tetrahedron Lett. 2008, 49, 5961.

23. Huang, H.; Jiang, H.; Chen, K.; Liu, H. J. Org. Chem. 2008, 73, 9061.

24. Carril, M.; Correa, A.; Bolm, C. Angew. Chem. Int. Ed. 2008, 47 , 4862.

25. Sawant, D. J.; Tambade, P. J.; Wagh, Y. S.; Bhanage, B. M. Tetrahedron Lett. 2010, 51, 2758.

26. Cho, C. S.; Kim, B. T.; Kim, T.-J.; Shim, S. C. J. Org. Chem. 2001, 66, 9020 .

27. Cho, C. S.; Kim, B. T.; Lee, M. J.; Kim, T.-J.; Shim, S. C. Angew. Chem. Int. Ed. 2001, 40, 958

28. Cho, C. S.; Kim, B. T.; Kim, T.-J.; Shim, S. C. Tetrahedron Lett. 2002, 43, 7987.

29. Cho, C. S.; Kim, B. T.; Kim, H.-S.; Kim, T.-J.; Shim, S. C. Organometallics 2003, 22, 3608.

30. Cho, C. S.; Lim, D. K.; Heo, N. H.; Kim, T.-J.; Shim, S. C. Chem Commun. 2004, 104

31. Cho, C. S. J. Organomet. Chem. 2005, 690, 4094.

32. Cho, C. S.; Shim, S. C. J. Organomet. Chem. 2006, 691, 4329.

33. Cho, C. S.; Patel, D. B. Tetrahedron 2006, 62, 6388.

34. Cho, C.S. J. Mol. Cat. A: Chem. 2007, 267, 49.

35. Cho, C. S. Catal. Commun. 2008, 9, 2261.

36. Cho, C. S.; Tran, N. T. Catal. Commun. 2009, 11, 191

37. Guan, J. T.; Yu, G-A.; Chen, L.; Weng, T. Q.; Yuan, J. J.; Liu, S. H. Appl. Organomet. Chem. 2009, 23, 75. 